\title{
Effect of Incorporation of Different Concentrations of Silver Nanoparticles as an Antimicrobial Agent on the Flexural and Impact Strength of Heat-Cured Denture Base Resin
}

\author{
Piyali Sarkar ${ }^{1}$ Sandeep Garg ${ }^{1} \quad$ Nidhi Mangtani Kalra ${ }^{1}$
}

${ }^{1}$ Department of Prosthodontics, MM College of Dental Sciences \&

Address for correspondence Piyali Sarkar, MDS, Department of Research, Ambala, Haryana, India Ambala 133203, Haryana, India (e-mail: dr.piyalisarkar16@gmail.com).

\begin{abstract}
Keywords

- silver nanoparticles

- impact strength

- flexural strength

Aim This article evaluates the effect of incorporating different concentrations of silver nanoparticles as an antimicrobial agent on the flexural and impact strength of heat-cured denture base resin.

Material and Methods A total of 80 specimens of polymethyl methacrylate resin were fabricated ( 40 for flexural strength and 40 for impact strength). Specimens were fabricated using stainless steel die of dimension $65 \mathrm{~mm} \times 10 \mathrm{~mm} \times 2.5 \mathrm{~mm}$ as per the American Dental Association specification no. 12, and $50 \mathrm{~mm} \times 6 \mathrm{~mm} \times 4 \mathrm{~mm}$ as per ISO 1567:1999 for flexural strength and impact strength, respectively, and were divided into four groups ( $A, B, C$, and D) based on the concentrations of silver nanoparticles $(0 \%, 2.5 \%, 5 \%$, and $10 \%)$. The specimens were subjected to three-point bending test and Izod impact tester for testing flexural and impact strength, respectively. Data obtained was compiled and analyzed using one-way analysis of variance and post hoc tests.

Results Results showed that for both the properties, maximum strength was observed in group A (control) followed by groups B and C, and minimum was observed in group D. A statistically significant difference in flexural strength was found among all the groups, whereas no statistically significant difference in impact strength was found among any of the groups.

Conclusion Within the limitations of this in vitro study, it was concluded that though incorporation of silver nanoparticles exhibited no effect on the impact strength of heat cure denture base resin, it decreased the flexural strength, so it should be used cautiously.
\end{abstract}

DOI https://doi.org/ $10.1055 / \mathrm{s}-0041-1733818$ ISSN 2321-1482
(C) 2021. Bhojia Dental College and Hospital affiliated to Himachal Pradesh University.

This is an open access article published by Thieme under the terms of the Creative Commons Attribution-NonDerivative-NonCommercial-License, permitting copying and reproduction so long as the original work is given appropriate credit. Contents may not be used for commercial purposes, or adapted, remixed, transformed or built upon. (https://creativecommons.org/licenses/by-nc-nd/4.0/).

Thieme Medical and Scientific Publishers Pvt. Ltd. A-12, 2nd Floor, Sector 2, Noida-201301 UP, India 


\section{Introduction}

Polymethyl methacrylate resin since its introduction has been an extremely popular material in the fabrication of complete denture, due to its certain desirable properties like easy manipulation, low cost, aesthetics, color stability, etc. Despite having certain superior properties it has some drawbacks also such as low thermal conduction, low modulus of elasticity, and affinity toward fastening of microbes to the impression surface. As the interior surface of the denture is not polished, it acts as the breeding ground for oral microorganisms, ${ }^{1}$ thereby permit the colonization of microorganisms that can prompt an inflammatory reaction in the oral mucosa of the denture wearers. ${ }^{2}$ Another critical aspect is the possible dissemination of pathogens from denture biofilm in immunocompromised patients which can cause severe systemic infections. Biofilm formation over complete dentures should be controlled by means of adequate cleaning methods and overnight removal. The methods advocated for cleaning the dentures include mechanical method, chemical method, and combination of the both. Mechanical method includes cleaning the denture with soft brush in presence of water or soap whereas chemical method includes the use of chemicals like alkaline peroxide, alkaline hypochlorite, acids, disinfectants, and certain enzymes. ${ }^{3}$ Neppelenbroek et $\mathrm{al}^{4}$ and Hanna ${ }^{5}$ have shown in their studies that chemical denture cleansers affect the hardness of denture base resins. Pisani et $\mathrm{al}^{6}$ also revealed similar results and stated that chemical denture cleansers have detrimental effects on the color stability, surface roughness, surface hardness, and flexural strength of denture base resin. Problems can also arise due to release of those substances from the resins leading to toxic effects on the oral mucosa as well. ${ }^{7}$ Hence, it would be convenient if denture base materials itself could prevent biofilm formation. ${ }^{1}$

Incorporation of antimicrobial agent to the denture base resin can become an alternative to those patients who are not able to clean their own dentures, that is, mentally and physically challenged patients and geriatric patients. ${ }^{8}$ The antimicrobial agents which can be incorporated into denture base resins are quaternary ammonium compound, antimicrobial monomer methacryloyloxyundecylpyridinium bromide, 2-tertbutylaminoethyl methacrylate (TBAEMA), silver vanadate ( $\beta$-AgVO3), thymoquinone, silver-zinc zeolite, and silver nanoparticles.

Silver has a history of use in human health care and medicine. However, it is not well documented as having any nutritional value. In ancient times, silver was used to store and purify water. Silver salts have been used since long against Gram-positive and Gram-negative bacteria, protozoa, fungi, as well as viruses because of their antimicrobial efficiency.

Nanotechnology has become a major focus in scientific research efforts nowadays. It has attributed to the improvement in materials used in medicine, as it can provide better functionality, mainly due to the nanometric sizes involved that exhibit different properties once they are applied to biological systems, compared with traditional systems of treatment. The nanoscale enables the materials to diffuse through different biological membranes, such as bacterial cell wall, and hence increases the bactericidal effects. ${ }^{9}$ Presently in dental applications, different forms of silver such as silver ions (Ag+), silver nanoparticles (AgNPs), and Ag-polymeric complexes have been used to improve the antibacterial efficiency. ${ }^{2}$ Silver nanoparticles are highly reactive due to large surface area and are synthesized by the reduction of silver ions using various methods, such as chemical reduction using chemical reducing agents, photochemical reduction, and radiolytic reduction by $\alpha$-rays or ultraviolet light. ${ }^{10}$

Though silver nanoparticles have been used by many authors as an effective antimicrobial agent by incorporating it into denture base material, its addition into it should not cause any change in physical and mechanical properties of the denture base material. Hence, the present study was planned to evaluate the effect of adding different concentrations of silver nanoparticles in the conventional heat cure denture base resin on its flexural and impact strength.

\section{Materials and Methodology}

To evaluate these properties, a total of 80 specimens of heat cure denture base resin were fabricated ( 40 for flexural

Table 1 Grouping of specimens for flexural and impact strength

\begin{tabular}{|l|l|l|l|}
\hline Sl. no. & Property to be evaluated & $\begin{array}{l}\text { Groups (based on the concentrations } \\
\text { of AgNPs added) }\end{array}$ & No. of specimens \\
\hline \multirow{2}{*}{1.} & Flexural strength & Group A: 0\% AgNPs & 10 \\
\cline { 3 - 4 } & & Group B: 2.5\% AgNPs & 10 \\
\cline { 3 - 4 } & & Group C: 5\% AgNPs & 10 \\
\cline { 3 - 4 } & & Group D: $10 \%$ AgNPs & 10 \\
\cline { 3 - 4 } & & Total & 40 \\
\hline \multirow{2}{*}{2.} & Group A: $0 \%$ AgNPs & 10 \\
\cline { 3 - 4 } & Group B: $2.5 \%$ AgNPs & 10 \\
\cline { 3 - 4 } & & Group C: $5 \%$ AgNPs & 10 \\
\cline { 3 - 4 } & Group D: $10 \%$ AgNPs & 40 \\
\hline
\end{tabular}

Abbreviation: AgNPs, silver nanoparticles. 
strength and 40 for impact strength). Before making specimens for each property, various concentrations of silver nanoparticles (Amnium Technologies Pvt. Ltd., Maharashtra, India), that is, $2.5,5$, and $10 \%$, were added to the denture base resin, and based on these concentrations, prepared specimens were divided into four groups for each property (-Table 1).

Methodology for preparation and evaluation of specimens for specified properties is as follows:

\section{Preparation of Gypsum Mold and Control Group Specimens}

Preformed stainless steel dies of dimension $65 \mathrm{~mm} \times 10 \mathrm{~mm}$ $\times 2.5 \mathrm{~mm}$ for flexural strength and $50 \mathrm{~mm} \times 6 \mathrm{~mm} \times 4 \mathrm{~mm}$ having $1.2 \pm 1 \mathrm{~mm}$ notch in the center for impact strength were used for preparing the gypsum mold ( $\mathbf{- F i g . 1}$ ). Once the mold was prepared a layer of separating media was applied on the mold, heat cure denture base resin was mixed as per the manufacturer's instructions, and packed into the gypsum mold in the dental flask. After packing, trial closure was performed until no flash was obtained. Later the flask was clamped, bench cured for 30 minutes, and transferred to an acrylizer for curing $\left(74^{\circ} \mathrm{C}\right.$ for 8 hours). After curing overnight, bench cooling was done, followed by careful deflasking and retrieval of acrylic specimens. Each specimen was carefully finished using acrylic trimming burs and finishing stones to final dimensions. The specimens were then inspected for any visible porosity, voids, or defect. Defected specimens were discarded and fresh specimens were fabricated. All the specimens were stored in distilled water for 24 hours for residual monomer elimination.

\section{Preparation of Heat Cure Specimens (Experimental Groups)}

A total of 30 specimens were prepared for each property (10 specimens for each group based on the concentration of silver nanoparticles added, that is, $2.5,5$, and $10 \%$, respectively). For each concentration the required amount of AgNPs were weighed on digital weighing machine and added to the denture base powder and was mixed thoroughly before mixing with monomer liquid. The remaining procedure was same as mentioned above.

\section{Testing of Specimens}

For flexural strength specimens were subjected to three-point bending test in a universal testing machine at a crosshead speed of $5 \mathrm{~mm} / \mathrm{min}$. The specimens were placed on a jig $40 \mathrm{~mm}$ apart. A load of $50 \mathrm{kgf}$ was applied by a centrally located rod until fracture occurred and values were recorded.

Flexural strength was calculated using the following formula:

$$
\mathrm{FS}=3 \mathrm{FL} / 2 \mathrm{bh}^{2}
$$

where, FS = flexural strength (MPa)

$\mathrm{F}=$ maximum load applied

$\mathrm{L}=$ distance between the support points $(40 \mathrm{~mm})$

$\mathrm{b}=$ specimen width $(10 \mathrm{~mm})$

$\mathrm{h}=$ thickness of the specimen $(2.5 \mathrm{~mm})$

For impact strength specimens were subjected to impact testing using Izod impact testing machine. For this, specimens were kept on the jig in such a way that the notch was facing toward the pendulum hammer. The force required by the pendulum to break the specimen was recorded for each specimen and impact strength was calculated using following formula:

$$
\mathrm{IS}=\mathrm{E} / \mathrm{wt}
$$

where IS = impact strength $\left(\mathrm{Kj} / \mathrm{m}^{2}\right)$

$\mathrm{E}=$ energy required to break the specimen (joule)

$\mathrm{w}=$ width $(\mathrm{mm})$

$\mathrm{t}=$ thickness of the specimen $(\mathrm{mm})$

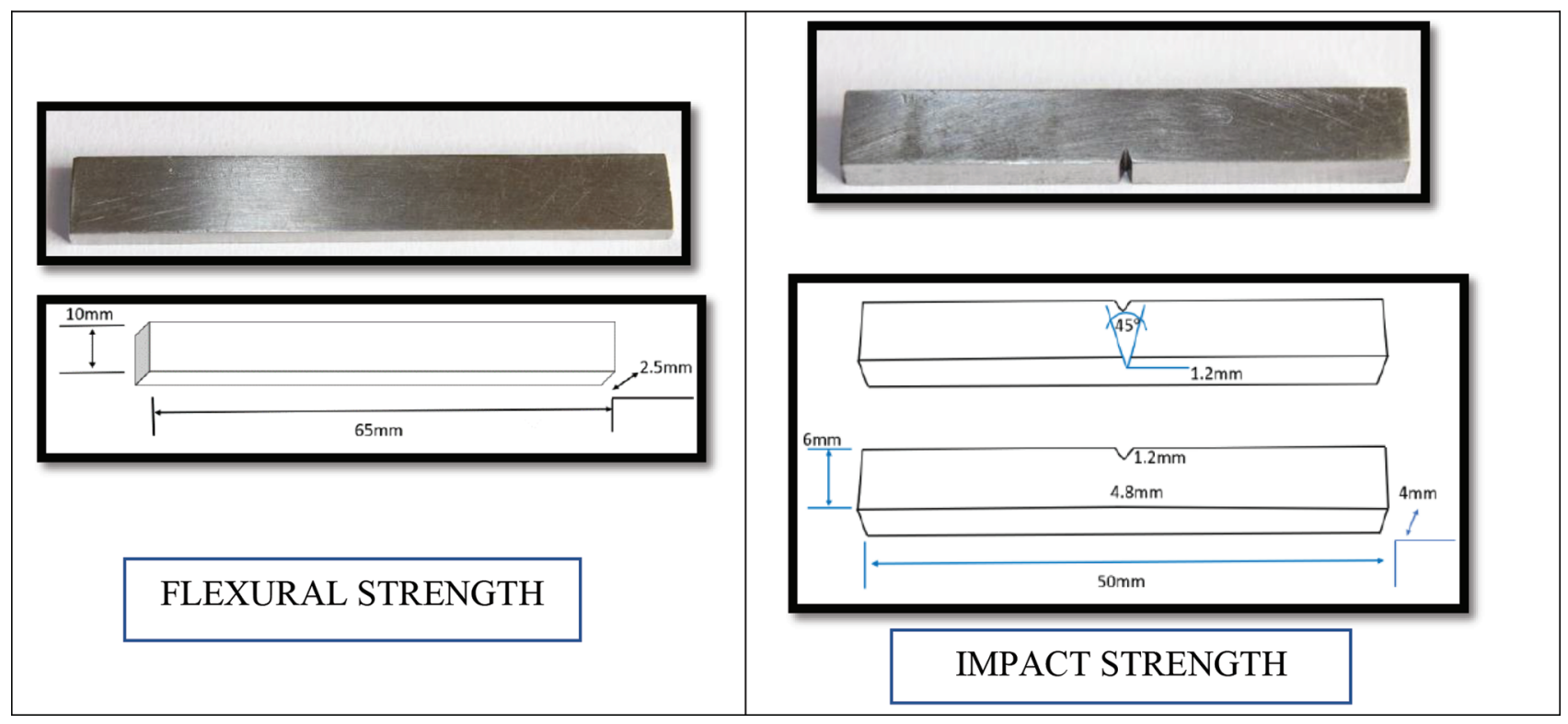

Fig. 1 Stainless steel dies for flexural and impact strength. 


\section{Mean Flexural Strength (MPa) of acrylic resin specimens after incorporation of various concentrations of silver nano particles}

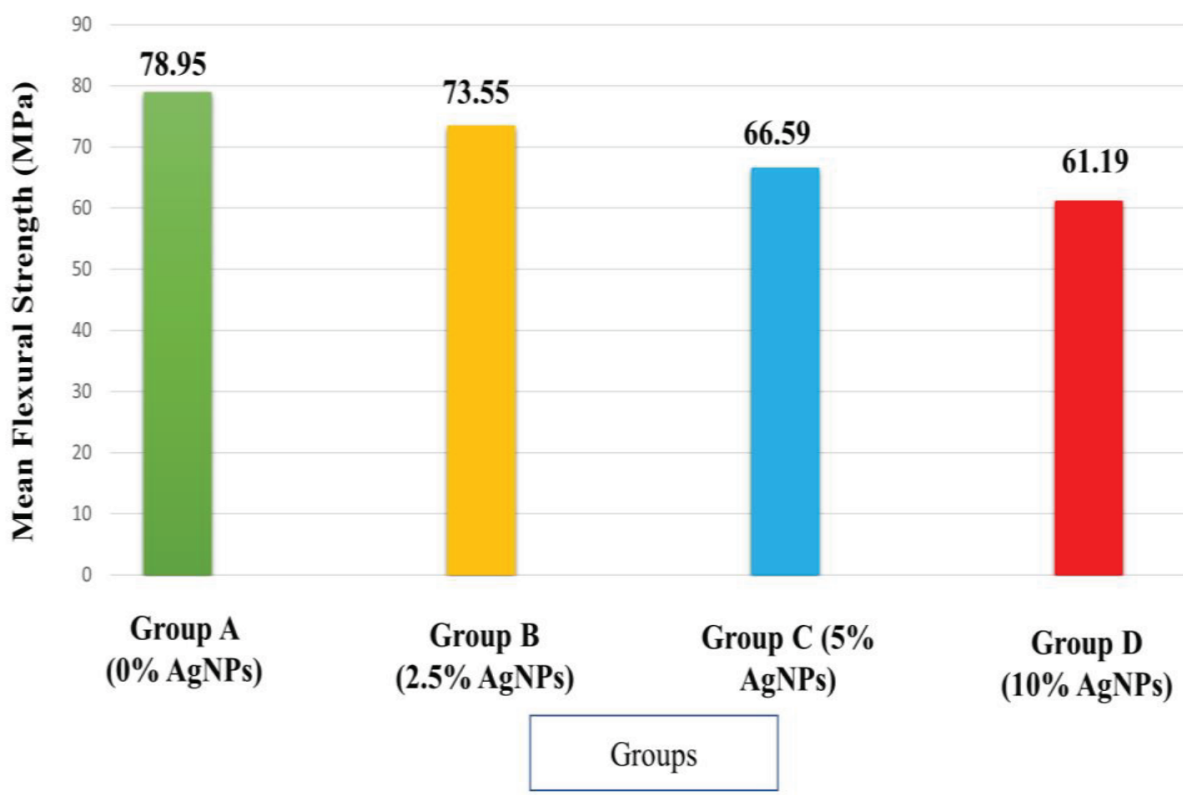

Fig. 2 Flexural strength test values.

Table 2 Mean of flexural strength (MPa) and impact strength $\left(\mathrm{Kj} / \mathrm{m}^{2}\right)$ of the acrylic resin specimens after incorporating different concentrations of silver nanoparticles

\begin{tabular}{|c|c|c|c|c|c|c|}
\hline \multirow[t]{2}{*}{ Groups } & \multirow[t]{2}{*}{$N$} & \multirow[t]{2}{*}{ Mean } & \multirow[t]{2}{*}{ Standard deviation } & \multirow[t]{2}{*}{ Standard error } & \multicolumn{2}{|c|}{ 95\% Confidence interval for mean } \\
\hline & & & & & Lower bound & Upper bound \\
\hline \multicolumn{7}{|c|}{ Flexural strength } \\
\hline $\begin{array}{l}\text { Group A } \\
0 \% \text { AgNPs }\end{array}$ & 10 & 78.9590 & 1.52780 & 0.48313 & 77.8661 & 80.0519 \\
\hline $\begin{array}{l}\text { Group B } \\
2.5 \% \text { AgNPs }\end{array}$ & 10 & 73.5570 & 1.61367 & 0.51029 & 72.4026 & 74.7114 \\
\hline $\begin{array}{l}\text { Group C } \\
5 \% \text { AgNPs }\end{array}$ & 10 & 66.5980 & 1.44260 & 0.45619 & 65.5660 & 67.6300 \\
\hline $\begin{array}{l}\text { Group D } \\
10 \% \text { AgNPs }\end{array}$ & 10 & 61.1970 & 1.57517 & 0.49811 & 60.0702 & 62.3238 \\
\hline \multicolumn{7}{|c|}{ Impact strength } \\
\hline $\begin{array}{l}\text { Group A } \\
0 \% \text { AgNPs }\end{array}$ & 10 & 11.9770 & 0.90416 & 0.28592 & 11.3302 & 12.6238 \\
\hline $\begin{array}{l}\text { Group B } \\
2.5 \% \text { AgNPs }\end{array}$ & 10 & 11.7320 & 0.95113 & 0.30077 & 11.0516 & 12.4124 \\
\hline $\begin{array}{l}\text { Group C } \\
5 \% \text { AgNPs }\end{array}$ & 10 & 11.6800 & 0.70985 & 0.22447 & 11.1722 & 12.1878 \\
\hline $\begin{array}{l}\text { Group D } \\
10 \% \text { AgNPs }\end{array}$ & 10 & 11.6550 & 0.55436 & 0.17530 & 11.2584 & 12.0516 \\
\hline
\end{tabular}

Abbreviation: AgNPs, silver nanoparticles.

\section{Results}

Statistical analysis was performed by using software SPSS version 25. Mean value of flexural and impact strength of acrylic resin specimens in each group was tabulated. Intergroup comparison was done using one-way analysis of variance (ANOVA) followed by post hoc Tukey's honest significant difference test. A $p$-value of $<0.05$ was considered significant in all tests. The results showed that maximum flexural strength and impact strength was observed in group A (control group) followed by groups $\mathrm{B}$ and $\mathrm{C}$, while the minimum was observed in group D (-Table 2, - Figs. 2 and 3). Results were highly significant for flexural strength, whereas no significant difference was found in any group of the impact strength (-Tables 3 and 4 ). 
Mean Impact Strength ( $\mathrm{KJ} / \mathrm{m}^{2}$ ) of acrylic resin specimens of all groups after incorporation of various concentrations of silver nano particles

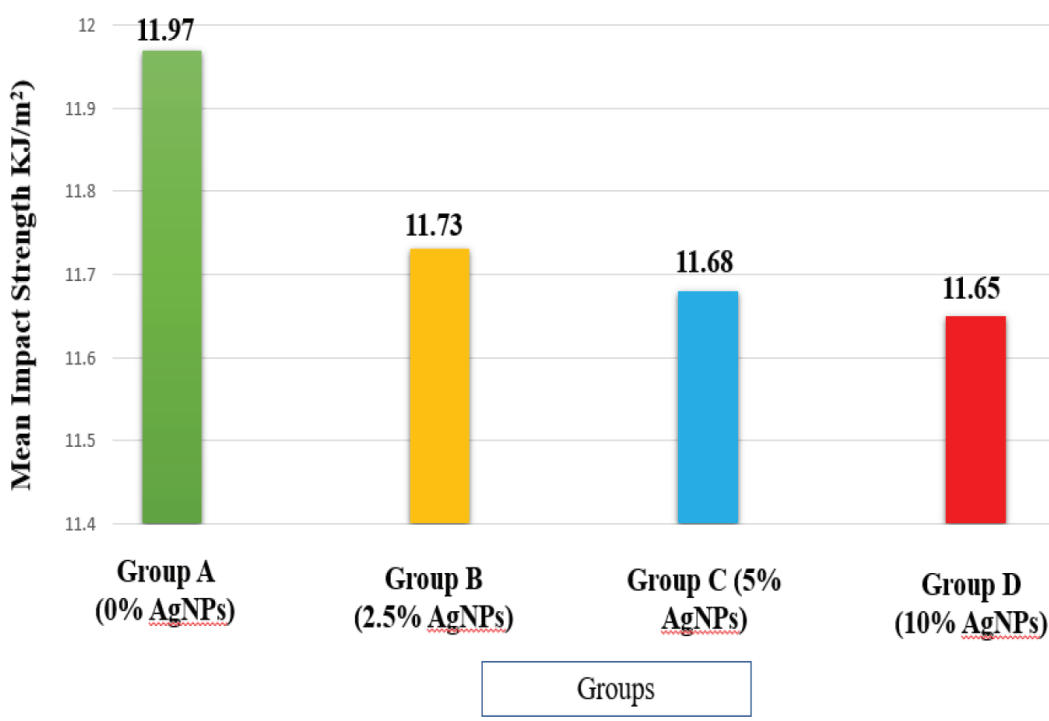

Fig. 3 Impact strength test values.

Table 3 Intergroup analysis of flexural strength and impact strength using one-way ANOVA

\begin{tabular}{|c|c|c|c|c|c|}
\hline & Sum of squares & $\mathrm{df}$ & Mean square & $F$ & Significance \\
\hline \multicolumn{6}{|l|}{ Flexural strength } \\
\hline Between groups & $1,819.582$ & 3 & 606.527 & 255.370 & 0.000 \\
\hline Within groups & 85.503 & 36 & 2.375 & & \\
\hline Total & $1,905.085$ & 39 & & & \\
\hline \multicolumn{6}{|l|}{ Impact strength } \\
\hline Betweengroups & 0.653 & 3 & 0.218 & 0.344 & 0.794 \\
\hline Within groups & 22.800 & 36 & 0.633 & & \\
\hline Total & 23.453 & 39 & & & \\
\hline
\end{tabular}

Abbreviations: ANOVA, analysis of variance; $\mathrm{df}$, degrees of freedom.

Table 4 Post hoc comparison

\begin{tabular}{|c|c|c|c|c|c|c|}
\hline \multirow[t]{2}{*}{ Group } & \multirow[t]{2}{*}{ Groups } & \multirow{2}{*}{$\begin{array}{l}\text { Mean } \\
\text { difference }\end{array}$} & \multirow[t]{2}{*}{ Standard error } & \multirow[t]{2}{*}{ Significance } & \multicolumn{2}{|c|}{ 95\% confidence interval } \\
\hline & & & & & Lower bound & Upper bound \\
\hline \multicolumn{7}{|c|}{ Flexural strength } \\
\hline \multirow[t]{3}{*}{ Group A } & Group B & $5.40200^{\mathrm{a}}$ & 0.68922 & 0.000 & 3.5458 & 7.2582 \\
\hline & Group C & $12.36100^{\mathrm{a}}$ & 0.68922 & 0.000 & 10.5048 & 14.2172 \\
\hline & Group D & $17.76200^{\mathrm{a}}$ & 0.68922 & 0.000 & 15.9058 & 19.6182 \\
\hline \multirow[t]{2}{*}{ Group B } & Group C & $6.95900^{\mathrm{a}}$ & 0.68922 & 0.000 & 5.1028 & 8.8152 \\
\hline & Group D & $12.36000^{\mathrm{a}}$ & 0.68922 & 0.000 & 10.5038 & 14.2162 \\
\hline Group C & Group D & $5.40100^{\mathrm{a}}$ & 0.68922 & 0.000 & 3.5448 & 7.2572 \\
\hline \multicolumn{7}{|c|}{ Impact strength } \\
\hline \multirow[t]{3}{*}{ Group A } & Group B & 0.24500 & 0.35590 & 0.901 & -0.7135 & 1.2035 \\
\hline & Group C & 0.29700 & 0.35590 & 0.838 & -0.6615 & 1.2555 \\
\hline & Group D & 0.32200 & 0.35590 & 0.802 & -0.6365 & 1.2805 \\
\hline \multirow[t]{2}{*}{ Group B } & Group C & 0.05200 & 0.35590 & 0.999 & -0.9065 & 1.0105 \\
\hline & Group D & 0.07700 & 0.35590 & 0.996 & -0.8815 & 1.0355 \\
\hline Group C & Group D & 0.02500 & 0.35590 & 1.000 & -0.9335 & 0.9835 \\
\hline
\end{tabular}

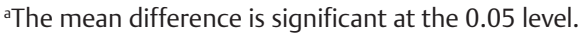




\section{Discussion}

Improvement in the field of medical science has led to an increase in the overall life expectancy of the elderly population. This has further lead to tremendous increase in elderly population, most of them being edentulous seeking prosthetic treatment. Rehabilitation of edentulous patients with complete denture is still the foremost choice because of its low cost and ease of fabrication. Average time period for which complete denture is in use is 5 years but it may need to be replaced early depending on maintenance of prosthesis and the oral condition of the patient. ${ }^{1}$ Since oral cavity is a niche for microorganisms, added prosthesis to it provides further area for accumulation of food debris and microorganisms. Therefore, denture cleansing plays an important role in the maintenance of prosthesis to improve its longevity and to maintain the overall health. ${ }^{2}$ Denture cleansing is the most important measure that should be taken by the denture wearers but it may be difficult to implement in some geriatric patients because of cognitive impairment, reduced motor dexterity, and memory loss. ${ }^{4}$ In such conditions, denture base resin with antimicrobial properties might help aged patients to improve their oral hygiene. Incorporating substances that could show antimicrobial activity into acrylic resin is a current trend to avoid denture stomatitis or related oral diseases. These include silver nanoparticles, methacrylic acid, chlorhexidine acetate, silver-zinc zeolites, acryl amide monomer, and TBAEMA. Casemiro et $\mathrm{al}^{8}$ evaluated the antimicrobial activity of different types of denture base resin after incorporating various percentages of silver-zinc zeolite and concluded that it was effective against all strains tested. Marra et al ${ }^{11}$ evaluated the antimicrobial activity of denture base resin incorporated with poly(2-tert-butylaminoethyl) and concluded that their incorporation had significant antimicrobial activity against Staphylococcus aureus and S. mutans biofilms. Monteiro et al ${ }^{12}$ reviewed the literature to determine the mechanism of action of various silver forms, that is, silver nanoparticles, as an antimicrobial agent and concluded that these could be used as effective antimicrobial agent for variety of promising applications. Kamikawa et $\mathrm{al}^{13}$ conducted a study to evaluate the adherence of Candida albicans and Candida glabrata on heat cure denture base resin incorporated with silver nanoparticles and concluded that denture-associated candidiasis can be prevented by incorporating silver nanoparticles to the denture base resin.

Several studies have shown that after incorporating a certain ratio of antimicrobial agent the physical and mechanical properties of the acrylic resin may get compromised.

Therefore, it is important to evaluate the mechanical properties of acrylic resins after incorporation of any material since complete and removable dentures are subjected to repeated flexural forces. Considering the above, the present study was done to evaluate the flexural and impact strength of heat cure denture base resin after incorporating different concentrations of silver nanoparticles as an antimicrobial agent.
In the present study, heat polymerized acrylic resin was used for the fabrication of the specimens. For flexural strength, the acrylic resin specimens were fabricated according to the American Dental Association specification no. 12 and subjected to three-point bending test to calculate flexural strength. The data obtained was subjected to statistical analysis for intragroup comparison using ANOVA and post hoc Tukey's test. Mean flexural strength at baseline for group A was $78.95 \mathrm{MPa}$ followed by group B (73.55 MPa), group C (66.59 MPa), and group D (61.19 MPa). Statistically significant difference in flexural strength was found among all the groups. Thus, it could be suggested from the present study that incorporation of silver nanoparticles is capable of altering the flexural strength of denture base resin, that is, with the increase in the concentrations of AgNPs, the flexural strength of heat cure denture base resin decreased. The present study is supported by Alla et $\mathrm{al}^{2}$ who evaluated the effect of addition of silver nanoparticles in heat cure denture base resins and found that the unmodified specimens had more flexural strength than the modified one. Köroğlu et al ${ }^{14}$ in their study evaluated the mechanical properties of denture base resin after incorporating different concentrations of silver nanoparticles and concluded that flexural strength of unmodified heat cure denture base resin was maximum and it decreased with increased concentration of silver nanoparticles.

For impact strength, the acrylic resin specimens of size $50 \mathrm{~mm} \times 6 \mathrm{~mm} \times 4 \mathrm{~mm}$ with a notch of $1.2 \mathrm{~mm}$ depth at the center of the specimen were fabricated according to ISO 1567:1999. The specimens were subjected to impact loading in Izod impact tester and impact strength was calculated. The data obtained was subjected to statistical analysis for intragroup comparison using ANOVA and post hoc Tukey's test. Mean impact strength at baseline for group A was $\left(11.97 \mathrm{Kj} / \mathrm{m}^{2}\right)$ followed by group $B\left(11.73 \mathrm{Kj} / \mathrm{m}^{2}\right)$, group $C\left(11.68 \mathrm{Kj} / \mathrm{m}^{2}\right)$, and group $\mathrm{D}\left(11.65 \mathrm{Kj} / \mathrm{m}^{2}\right)$. No statistical significant difference in impact strength was found among the groups. Thus, it could be suggestive that incorporation of different concentrations of silver nanoparticles had no effect on impact strength of denture base resin. This is supported by Köroğlu et $\mathrm{al}^{14}$ who evaluated the mechanical properties of denture base resin after incorporating different concentrations of AgNPs and concluded that addition of AgNPs had no significant effect on impact strength of heat cure denture base resin.

\section{Limitations}

1. Being an in vitro study, true simulation of oral conditions were not possible, even prepared specimens did not truly represent complex shape of the denture.

2. Only two properties were evaluated. Other properties such as surface roughness, color, and surface hardness may also get affected after incorporation of silver nanoparticles and needed to be studied.

3. Effect of incorporation of silver nanoparticles is studied only on one type of denture base resin. 


\section{Conclusion}

Within the limitations of the present in vitro study the following conclusions can be drawn:

1. Maximum flexural strength was observed in group A (control) followed by groups B and $C$ and minimum was observed in group D. A statistically significant difference in flexural strength was found among all the groups.

2. Maximum impact strength was observed in group A (control) followed by groups B and C, and minimum was observed in group D. No statistically significant difference in impact strength was found among any of the groups.

3. Though incorporation of silver nanoparticles exhibited no effect on the impact strength of heat cure denture base resin, it decreased flexural strength, so should be used cautiously. Further studies are required, using various concentrations of silver nanoparticles on other physical and mechanical properties of different types of denture base resins to help the clinician to choose the concentration of antimicrobial agent.

\section{Conflict of Interest}

None declared.

\section{References}

1 Regis RR, Zanini AP, Della Vecchia MP, Silva-Lovato $\mathrm{CH}$, Oliveira Paranhos HF, de Souza RF. Physical properties of an acrylic resin after incorporation of an antimicrobial monomer. J Prosthodont 2011;20(5):372-379

2 Alla KR, Swamy KR, Vyas R, Konakanchi A, Guduri V, Gadde P. Influence of silver nano particles incorporation on flexural strength of heat-cure acrylic denture base resin materials. Annu Res Rev Biol 2017;22:1-8

3 Gajwani- Jain S. Magdum D, Karagir A, Pharane P. Denture cleansers: a review. IOSR-JDMS 2015;1(14):94-96

4 Neppelenbroek KH, Pavarina AC, Vergani CE, Giampaolo ET. Hardness of heat-polymerized acrylic resins after disinfection and long-term water immersion. J Prosthet Dent 2005;93(2):171-176

5 Hanna BA. Evaluation of the effect of two different disinfectant solutions on the surface hardness of the denture base acrylic resin. J Kerbala Uni 2011;9(2):117-123

6 Pisani MX, Silva CH, Paranhos HD, Souza RF, Macedo AP. The effect of experimental denture cleanser solution Ricinus communis on acrylic resin properties. Mater Res 2010;13(3):369-373

7 Pesci-Bardon C, Fosse T, Serre D, Madinier I. In vitro antiseptic properties of an ammonium compound combined with denture base acrylic resin. Gerodontology 2006;23(2):111-116

8 Casemiro LA, Gomes Martins CH, Pires-de-Souza FdeC, Panzeri H. Antimicrobial and mechanical properties of acrylic resins with incorporated silver-zinc zeolite - part I. Gerodontology 2008;25(3):187-194

9 Nuñez-Anita RE, Acosta-Torres LS, Vilar-Pineda J, Martínez-Espinosa JC, de la Fuente-Hernández J, Castaño VM. Toxicology of antimicrobial nanoparticles for prosthetic devices. Int J Nanomedicine 2014;9:3999-4006

10 Kumar V, Jolivalt C, Pulpytel J, Jafari R, Arefi-Khonsari F. Development of silver nanoparticle loaded antibacterial polymer mesh using plasma polymerization process. J Biomed Mater Res A 2013;101(4):1121-1132

11 Marra J, Paleari AG, Rodriguez LS, Leite AR, Pero AC, Compagnoni MA. Effect of an acrylic resin combined with an antimicrobial polymer on biofilm formation. J Appl Oral Sci 2012;20(6):643-648

12 Monteiro DR, Gorup LF, Takamiya AS. Ruvollo-Filho AC, de Camargo ER, Barbosa DB. The growing importance of materials that prevent microbial adhesion: antimicrobial effect of medical devices containing silver. Int J Antimicrob Agents 2009;34(2):103-110

13 Kamikawa Y, Hirabayashi D, Nagayama T, et al. In vitro antifungal activity against oral candida species using a denture base coated with silver nanoparticles. J Nanomater 2014;1(1):1-6

14 Köroğlu A, Şahin O, Kürkçüoğlu I, Dede DÖ, Özdemir T, Hazer B. Silver nanoparticle incorporation effect on mechanical and thermal properties of denture base acrylic resins. J Appl Oral Sci 2016;24(6):590-596 